\title{
Use of a word reading task for studying word recognition
}

\author{
ROBERT F. LORCH, JR. \\ University of Kentucky, Lexington, Kentucky
}

(Susan M. Belmore, Sponsor)

\begin{abstract}
A new experimental procedure is introduced for studying word recognition. On each trial in the word reading task, subjects are presented a target word, and their response latency, indicating when they have read the word, is recorded. Two experiments demonstrated the sensitivity of the procedure. In Experiment 1, subjects responded faster to frequent words than to infrequent words, and the frequency effect was greater for long words than for short words. In Experiment 2, responses were faster to a target word if it was preceded by a related, rather than an unrelated, word. Furthermore, reaction times were slower if the target was degraded rather than intact. The word reading task is a potentially less complicated experimental procedure than the lexical decision and naming tasks because it eliminates the binary decision and verbal production demands of those tasks.
\end{abstract}

The lexical decision task (Meyer \& Schvaneveldt, 1971) and the naming task (Forster \& Chambers, 1973) have frequently been used to study word recognition processes. Recent evidence suggests that processes operating after lexical access is complete play important roles in each task. These postlexical access processes complicate the interpretation of results from lexical decision and naming experiments. The purpose of the present study is to test the validity of a new experimental procedure that may avoid some of the limitations of the lexical decision and naming tasks.

Investigators using the lexical decision task have often assumed a simple model of how a lexical decision is made. When a letter string is presented, the subject encodes the string and searches lexical memory for a corresponding representation. If a subject finds a representation that matches the stimulus, a "word" response is given; if the subject fails to locate a match, a "nonword" response is given. According to this model, the subject's decision on a given trial is directly determined by the outcome of the lexical search. Stimulus variables are generally interpreted as affecting either encoding or the search of the lexicon (Becker, 1979; Morton, 1969).

Despite the plausibility of this processing model, there is abundant evidence that lexical decision performance is not such a direct indicator of the processes of lexical access. First, subjects can adopt different decision strategies depending upon the stimuli used in the experiment (Chumbley \& Balota, 1984; Hudson \& Bergman, 1985;

I would like to express my appreciation to the following people for their helpful comments on an earlier draft of this manuscript: Susan M. Belmore, Robert Crowder, Kenneth Forster, and Henry L. Roediger III. Requests for reprints should be addressed to: R. F. Lorch, Jr., Department of Psychology, University of Kentucky, Lexington, KY 40506-0044.
Kinoshita, Taft, \& Taplin, 1985). Second, many effects in lexical decision appear attributable to processes occurring after lexical access is complete (Balota \& Chumbley, 1984; Kinoshita et al., 1985; Lupker, 1984; Seidenberg, Waters, Sanders, \& Langer, 1984; West \& Stanovich, 1982). In keeping with these findings, recent models of performance in lexical decision emphasize the central role that decision processes play in the task (Balota \& Chumbley, 1984; Kinoshita et al., 1985).

Because the effects of variables on decision processes may obscure effects on lexical access, a preferable paradigm would be one that requires lexical access while minimizing the role of decision processes. For this reason, the word naming task has become increasingly popular as a paradigm for studying word recognition (Balota $\&$ Lorch, in press; Lupker, 1984; Seidenberg et al., 1984). However, the naming task also has limitations. Under some conditions, the naming task may not even involve lexical access processes (Hudson \& Bergman, 1985). Furthermore, there is evidence that the production processes required by naming may be the locus of some effects in the task (Balota \& Chumbley, 1985). Thus, postlexical processing also complicates interpretation of results from naming experiments.

The present investigation examined a potential alternative task to lexical decision and naming. The word reading task has direct analogs in the various word-by-word presentation procedures that have been used to study text processing (Aaronson \& Scarborough, 1976; Haberlandt \& Graesser, 1985; Just, Carpenter, \& Woolley, 1982). On each trial in the word reading task, a single word is presented and the subject's task is simply to press a response key as soon as the word is identified. Response time is the dependent measure. Like the lexical decision and naming tasks, the word reading task requires the subject to access the lexical representation of a stimulus word 
and, therefore, should be sensitive to factors affecting word recognition processes. However, the reading task should eliminate the binary decision processes involved in lexical decision and the articulatory processes required by naming. Thus, it has the potential to be a more straightforward method for studying word recognition than its two predecessors.

Despite the potential advantages of the word reading task, it has not been used previously. One probable reason for this is skepticism concerning whether the task would be sensitive to variables influencing word recognition. Because the task relies on subjects' self-reports regarding when they have "read" a word on a trial, the procedure potentially permits wide variation in response criteria both within and across subjects. Although findings from single-word text-presentation experiments are encouraging, it may be that subjects' criteria for response are more stable in such procedures because their processing is guided by text-comprehension goals. Thus, the purpose of this investigation was to determine the potential of the word reading task as procedure for studying word recognition.

\section{EXPERIMENT 1}

Experiment 1 investigated the effects on word reading time of a word's frequency of usage and length in letters. Although recent studies demonstrate that word frequency and length have effects on decision processes in lexical decision and production processes in naming, the same investigations suggest that both variables also affect earlier stages of processing (Balota \& Chumbley, 1984, 1985; Hudson \& Bergman, 1985). Thus, the reading task should be sensitive to frequency and length if it is a valid procedure for studying word recognition.

\section{Method}

Subjects. Subjects were 19 students, solicited from introductory psychology courses at the University of Kentucky.

Apparatus. All stimulus presentation and data collection were controlled by an Apple II+ microcomputer which was interfaced with a Zenith data systems video monitor. A Mountain Hardware timing board was used to obtain reaction times to the nearest millisecond.

Materials. Stimuli were selected from the Kučera and Francis (1967) norms to vary orthogonally with respect to frequency of usage and length in letters. Half of the 160 critical items were 3-5 letters long $(M=3.875)$, and half were 8-14 letters long $(M=9.45)$. Half of the words occurred 1 or 2 times per million $(M=1.85)$, and half occurred at least 131 times per million $(M=222.44)$. An additional 24 items with similar characteristics were selected as practice items.

Procedure. Each subject participated individually in an experimental session lasting approximately $20 \mathrm{~min}$. Subjects were told that they would be presented a single word on each trial and that their task was to press the space bar on the computer's keyboard as soon as they read the word to themselves. Subjects were instructed that they would occasionally be asked to recall a word immediately after they pressed the space bar. It was emphasized that they should not attempt to memorize each word because they would have no difficulty recalling a word as long as they had paid attention to the word when it was presented. The experimenter remained in the lab room throughout the practice block to provide any necessary clarification of the procedure.

The sequence of events was the same on every trial: (1) a row of three asterisks was presented in the center of the video monitor for $200 \mathrm{msec}$; (2) after a 200-msec delay, a tone was presented for $140 \mathrm{msec}$; (3) after a 200-msec delay, the stimulus word was presented in the center of the video monitor until the subject pressed the space bar; (4) pressing the space bar immediately erased the word and replaced it with three rows of asterisks which served to mask the portion of the screen where the word had been; (5) the mask of asterisks was presented for $500 \mathrm{msec}$, and then erased; (6) if the trial did not require a recall test and the subject did not take more than $1 \mathrm{sec}$ to respond, the next trial began after an interval of $2 \mathrm{sec}$. On recall trials, a message was presented, requesting that the subject type the just-presented word on the keyboard. After the subject typed the word, the computer displayed the correct response for $1,500 \mathrm{msec}$ before initiating the next trial. Recall trials occurred at random with a probability of .25 . On trials in which the subject took longer than $1 \mathrm{sec}$ to respond, the following message was displayed: "Your response time was over 1 second. Please try to respond more quickly. (Press the space bar to go on.)" The next trial was initiated after the subject pressed the space bar. The order of presentation of words within each of the four blocks of critical stimuli was randomized independently for each subject.

\section{Results and Discussion}

Reaction times longer than $1 \mathrm{sec}$ were replaced by the subject's mean reaction time for the condition. In the case of 2 subjects, more than $5 \%(6.25 \%$ and $11.25 \%)$ of the critical trials involved reaction times exceeding the 1 -sec cutoff. The data of these 2 subjects were excluded from all analyses, because it was reasoned that they were not responding immediately upon reading a word. Across the remaining subjects, only $1.54 \%$ of all the critical trials involved times exceeding $1 \mathrm{sec} ; 73.8 \%$ of these slow responses occurred to long, uncommon words. Subjects also made very few errors on the recall trials: Excluding obvious spelling errors, recall errors occurred on only $2.2 \%$ of the 803 test trials across subjects.

The mean reaction times are presented as a function of condition in Table 1. A repeated-measures ANOVA was conducted on the data. All reported tests are reliable at or beyond the .05 level unless otherwise noted. Although the main effects of frequency and length were both significant, the basic result of the experiment was that the two variables interacted $[F(1,16)=9.58, M S e=295$ for subjects; $F(1,156)=6.83, M S e=825$ for items]. As seen in Table 1 , there was virtually no effect of word frequency for the short words (both $F \mathrm{~s}<1$ ), whereas frequent long words were responded to $25 \mathrm{msec}$ faster than infrequent long words $[F(1,16)=12.05, M S e=525$ for subjects; $F(1,156)=15.55, M S e=825$ for items].

The observed effects of frequency and length are consistent with findings for both the lexical decision task (e.g., Whaley, 1978) and the naming task (e.g., Balota \& Chumbley, 1984; Forster \& Chambers, 1973). Fur-

Table 1

Mean Reaction Times as a Function of Word Frequency and Length

\begin{tabular}{lccc} 
& \multicolumn{3}{c}{ Word Frequency } \\
\cline { 2 - 4 } Length & High & Low & Mean \\
\hline Short & 359 & 360 & 359.5 \\
Long & 423 & 450 & 436.5 \\
Mean & 391 & 405 & 398 \\
\hline
\end{tabular}


thermore, the interaction of frequency and length is similar to that found when text is presented using the moving window paradigm (Haberlandt \& Graesser, 1985). These results indicate that subjects can adopt stable criteria for responding in the word reading task. They provide an initial demonstration that the task may be a viable, sensitive procedure for studying word recognition processes.

\section{EXPERIMENT 2}

Experiment 2 provided a further test of the word reading task. It examined the effects on word recognition of two additional variables, stimulus quality and context. On each trial in the experiment, a prime word, which was either associatively related or unrelated to the target word, was presented. In addition, stimulus quality was manipulated by presenting the target either intact or with asterisks placed between successive letters (see Stanovich \& West, 1983). Assuming that context and stimulus quality affect word recognition processes and that the priming paradigm can be used successfully with the word reading task, the effects of the two variables should be consistent with those found in the lexical decision and naming tasks. Specifically, reaction times should be faster to words following a related prime than following an unrelated prime, and the effect of context should be greater when the target word is degraded rather than intact (e.g., Becker \& Killion, 1977; Meyer, Schvaneveldt, \& Ruddy, 1975).

\section{Method}

Subjects. Subjects were 34 students, solicited from introductory psychology courses at the University of Kentucky.

Materials. Stimulus-response word pairs were selected from singleresponse word association norms (Jenkins, 1970; Keppel \& Strand, 1970; Postman, 1970). Stimulus words served as primes in the word reading experiment, and responses served as target words. There were 100 word pairs selected for use as critical items and 20 pairs selected for use as practice items. Target words were 1 or 2 syllables and between 3 and 9 letters long.

Four lists were constructed from the word pairs. Each list began with the same block of 20 practice items and included two blocks of 50 target items each. Half of the target words in each list were degraded by inserting asterisks between adjacent letters (e.g., KING-Q*U*E*E*N) and half of the target words did not include asterisks (e.g., BREAD-BUTTER). Half of the prime-target pairs were related and half were unrelated. Unrelated pairs were created by randomly re-pairing the prime and target words of the original word pairs. The assignment of targets to the four experimental conditions was counterbalanced across the four lists. The order or presentation of the two blocks of critical pairs was counterbalanced across subjects, and the order of presentation of items within each block was randomized independently for each subject.

Procedure. Subjects were instructed that they would see two words on each trial and that they should read the first word silently, then press the space bar as soon as they had read the second word. The sequence of events on each trial was identical to that of Experiment 1, with the exception of the addition of the prime word. After presentation of the warning tone, the prime word was presented for a duration of $500 \mathrm{msec}$. The prime word was then erased and the target word was immediately presented. In all other respects, the procedure was identical to that of the first experiment.

\section{Results and Discussion}

The procedure for analyzing the data was analogous to that of Experiment 1. The data of 2 subjects were excluded because they exceeded the 1-sec cutoff too often (7\% in each case). Across the remaining subjects, only $0.78 \%$ of all critical trials involved times exceeding $1 \mathrm{sec}$. Of the total of 25 slow responses, 20 occurred on trials in which the stimulus was degraded. Once again, subjects made very few errors on recall trials $(2 \%)$.

The reaction time results are summarized in Table 2 . A repeated-measures ANOVA demonstrated that subjects responded more slowly to a target if it was degraded than if it was intact $[F(1,31)=20.78, M S \mathrm{e}=806$ for subjects; $F(1,99)=58.29, M S e=882$ for items]. Second, subjects were faster to respond to a target if it was preceded by a related word than if it was preceded by an unrelated word $[F(1,31)=4.26, M S e=206$ for subjects; $F(1,99)=5.09, M S \mathrm{e}=623$ for items.] The interaction of context and stimulus quality did not approach significance.

The finding that stimulus quality and context influenced reaction time is consistent with previous findings (e.g., Becker \& Killion, 1977; West \& Stanovich, 1982) and provides a further demonstration that the task is sensitive to variables assumed to influence encoding processes. The failure to observe an interaction of the two variables is probably due to the small effect of context. There are at least two possible reasons for the small context effect. First, semantic context affects encoding or lexical access, but the word reading task may not be very sensitive to such effects. However, there were several indications that the procedure is very sensitive to the effects of other variables on word recognition processes (see the following section). Second, perhaps the robust context effects found in lexical decision and naming are due to postlexical access processes operating in those tasks. This issue cannot be resolved with the present findings.

\section{GENERAL DISCUSSION}

A new experimental procedure has been introduced for studying word recognition processes. The purpose of the present investigation was to test whether the word reading task is sensitive to variables presumed to influence lexical access processes. The results demonstrate that it is. Reading times decreased as word frequency increased and as word length decreased. Furthermore, the effect of frequency was greater for long words than for short words. In addition, reading times depended upon the visual clarity of the target word and the context in which the target was presented. These results are consistent with many previous findings from the lexical decision and naming tasks. Although there was

Table 2

Mean Reaction Times as a Function of Stimulus Quality and Context

\begin{tabular}{lccc}
\hline & \multicolumn{3}{c}{ Stimulus Quality } \\
\cline { 2 - 4 } Context & Intact & Degraded & Mean \\
\hline Related & 522 & 542 & 532 \\
Unrelated & 524 & 550 & 537 \\
Mean & 523 & 546 & 534 \\
\hline
\end{tabular}


initial concern that subjects would not be motivated to concentrate in the simple task, there was little evidence of lack of attention on the part of the subjects. Rarely did a reading time exceed $1 \mathrm{sec}$ and rarely did subjects fail to recall a word they had just seen. Finally, the primary concern with the procedure was that subjects might not adopt a consistent criterion for responding in the task. This concern was also unfounded, as shown by consistently low variability in the observed effects across the two experiments (e.g., the standard error for the test of the context effect in Experiment 2 was $2.54 \mathrm{msec}$ ).

Despite these encouraging results, important questions remain regarding the validity of the procedure. As mentioned earlier, the small effect of context in Experiment 2 requires further investigation. Most critical is the issue of whether the word reading task really does minimize postlexical processing. Although the task eliminates the binary decision demands of lexical decision and the verbal production requirements of naming, it does require some postlexical processing. Specifically, the subject must adopt some criterion for deciding when a target word has been read and a response should be executed. Thus, empirical tests of the potential role of postlexical processing must be conducted. A strategy for conducting such tests would be to select variables known to influence postlexical processing in lexical decision and naming tasks and to compare the effects of the variables on word reading, lexical decision, and naming (e.g., Balota \& Lorch, in press; Lupker, 1984; Seidenberg et al., 1984). If effects are observed for lexical decision and naming but not for word reading, it would suggest that the variables influence processes which are unique to lexical decision and naming.

If the word reading task proves to be a sensitive procedure, relatively free of postlexical influences on performance, then it should be useful in two ways. First, it has the potential to permit more direct examination of word recognition processes than does the lexical decision or naming task. Second, it might be used in conjunction with the lexical decision and naming tasks to test hypotheses concerning the locus of effects of experimental manipulations. Future research should proceed by comparing performance in the word reading task with performance in the lexical decision and naming tasks.

\section{REFERENCES}

Aaronson, D., \& SCARborough, H. S. (1976). Performance theories for sentence coding: Some quantitative evidence. Journal of Experimental Psychology: Human Perception \& Performance, 2, 56-70.

Balota, D. A., \& Chumbley, J. I. (1984). Are lexical decisions a good measure of lexical access? The role of word frequency in the neglected decision stage. Journal of Experimental Psychology: Human Perception \& Performance, 10, 340-357.

BALOTA, D. A., \& ChUMbley, J. I. (1985). The locus of word-frequency effects in the pronunciation task: Lexical access and/or production frequency? Journal of Memory \& Language, 24, 89-106.

BALOTA, D. A., \& LoRCH, R. F., JR. (in press). The depth of spreading activation: Mediated priming effects in pronunciation but not in lexical decision. Journal of Experimental Psychology: Learning, Memory, \& Cognition.

BeCKER, C. A. (1979). Semantic context and word frequency effects in visual word recognition. Journal of Experimental Psychology: Human Perception \& Performance, 5, 252-259.
BECKER, C. A., \& KILLION, T. H. (1977). Interaction of visual and cognitive effects in word recognition. Journal of Experimental Psychology: Human Perception \& Performance, 3, 389-401.

Chumbley, J. I., \& Balota, D. A. (1984). A word's meaning affects the decision in lexical decision. Memory \& Cognition, 12, $590-606$.

Forster, K. I., \& Chambers, S. M. (1973). Lexical access and naming time. Journal of Verbal Learning \& Verbal Behavior, 12, 627-635.

Haberlandt, K. F., \& Graesser, A. C. (1985). Component processes in text comprehension and some of their interactions. Journal of Experimental Psychology: General, 114, 357-374.

Hudson, P. T. W., \& Bergman, M. W. (1985). Lexical knowledge in word recognition: Word length and word frequency in naming and lexical decision tasks. Journal of Memory \& Language, 24, 46-58.

Jenkins, J. J. (1970). The 1952 Minnesota word association norms. In L. Postman \& G. Keppel (Eds.), Norms of word association. New York: Academic Press.

Just, M. A., Carpenter, P. A., \& Woolley, J. D. (1982). Paradigms and processes in reading comprehension. Journal of Experimental Psychology: General, 111, 228-238.

KePPEL, G., \& STRAND, B. Z. (1970). Free-association responses to the primary responses and other responses selected from the PalermoJenkins norms. In L. Postman \& G. Keppel (Eds.), Norms of word association. New York Academic Press.

Kinoshita, S., TAFT, M., \& TAPLin, J. E. (1985). Nonword facilitation in a lexical decision task.-Journal of Experimental Psychology: Learning, Memory, \& Cognition, 11, 346-362.

KuČERA, H., \& Francis, W. N. (1967). Computational analysis of present-day American English. Providence: Brown University Press.

LUPKER, S. J. (1984). Semantic priming without association: A second look. Journal of Verbal Learning \& Verbal Behavior, 23, 709-733.

MeYer, D. E., \& SChVANEVELDT, R. W. (1971). Facilitation in recognizing pairs of words: Evidence of a dependence between retrieval operations. Journal of Experimental Psychology, 90, 227-234.

Meyer, D. E., Schvaneveldt, R. W., \& Ruddy, M. G. (1975). Loci of contextual effects on visual word recognition. In P. M. A. Rabbitt $\& S$. Dornic (Eds.), Attention and performance $V$. London: Academic Press.

MORTON, J. (1969). The interaction of information in word recognition. Psychological Review, 86, 165-178.

Postman, L. (1970). The California norms: Association as a function of word frequency. In L. Postman \& G. Keppel (Eds.), Norms of word association. New York: Academic Press.

Seidenberg, M. S., Waters, G. S., Sanders, M., \& Langer, P. (1984). Pre- and postlexical loci of contextual effects on word recognition. Memory \& Cognition, 12, 315-328.

Stanovich, K. E., \& WeSt, R. F. (1983). On priming by a sentence context. Journal of Experimental Psychology: General, 112, 1-36.

West, R. F., \& Stanovich, K. E. (1982). Source of inhibition in experiments on the effect of sentence context on word recognition. Journal of Experimental Psychology: Learning, Memory \& Cognition, 8 , 385-399.

Whaley, C. P. (1978). Word-nonword classification time. Journal of Verbal Learning \& Verbal Behavior, 17, 143-154.

(Manuscript received for publication September 20, 1985.) 